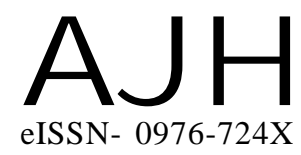

Article history :

Received : 17.06.2016

Revised : 10.10 .2016

Accepted : 24.10.2016

AUTHOR FOR CORRESPONDENCE

S. MALATHI

Horticultural Research Station

(T.N.A.U.), OOTY, (T.N.) INDIA

Email : malathi_agri@rediffmail.com
THEASIAN JOURNALOF HORTICULTURE

Volume 11 | Issue 2 | December, 2016 | 288-294

Visit us -www.researchjournal.co.in

RESEARCH PAPER

DOI : 10.15740/HAS/TAJH/11.2/288-294

\title{
Analysis of genetic diversity among the isolates of Pseudomonas fluorescens isolated from onion rhizosphere region
}

\section{S. MALATHI}

ABSTRACT : Pseudomonas fluorescens was isolated from different onion growing areas of Tamil Nadu, India and they were screened against Fusarium oxysporum f.sp.cepae in vitro. RAPD analysis was carried out using twelve random primers, each of them consisted of 10 base pairs. Analysis of the genetic co-efficient matrix derived from the scores of RAPD profile, showed that minimum and maximum per cent similarities among Pseudomonas fluorescens isolates were in the range of 10 to 92 per cent, respectively. Cluster analysis by using the unweighted pair-group method with arithmetic average (UPGMA), clearly separated the isolates into 2 major clusters (A and B) confirming the genetic diversity among the isolates of Pseudomonas fluorescens isolated from onion.

KEY WORDS : Pseudomonas fluorescens, Onion rhizosphere soil, Genetic diversity, RAPD

HOW TO CITE THIS ARTICLE : Malathi, S. (2016). Analysis of genetic diversity among the isolates of Pseudomonas fluorescens isolated from onion rhizosphere region. Asian J. Hort., 11(2) : 288-294, DOI : 10.15740/HAS/TAJH/11.2/288-294. 